\title{
SISTER TALK: INVESTIGATING AN OLDER SIBLING'S RESPONSES TO VERBAL CHALLENGES
}

\author{
AUGUST 2017 \\ Version 2 \\ 10,000 words
}

Joanna Friedland

j.friedland@nhs.net

Dr Merle Mahon

merle.mahon@ucl.ac.uk

Tel +44 (0) 2076794036

\section{Correspondence address:}

Joanna Friedland

Language and Cognition Research Department

University College London

Chandler House, 2 Wakefield street

London WC1N 1PF

Joanna Friedland is a Speech and Language Therapist at St Pancras Hospital, London.

Merle Mahon is Senior Lecturer in UCL's Division of Psychology and Language Science. 


\section{Abstract}

Children's linguistic and social skills develop through play with siblings, but there is little research into sibling interaction using naturally-occurring data. This Conversation Analytic case study presents an evidence-based account of how an older sibling responds to verbal challenges from her younger sibling during free-play at home.

The older sibling employs prosodic, rhetorical and linguistic devices to deflect challenges whilst avoiding conflict. She does this by acknowledging the grounds of the challenge, before invoking privileged information or epistemic differences to reject it. Structurally, the older sibling inserts extended digressions which obfuscate challenges by engaging the challenger and switching topic. These phenomena blur the traditional accept/reject response dichotomy.

The findings provide insight into the complexity of a five-/six-year-old's challenge-defence strategies and highlight the importance of face preservation and mitigation of disagreement. We propose that the ability to respond to challenges while maintaining intersubjectivity is a component of communicative competence.

Key words: child language; conversation analysis; verbal challenge; disagreement; obfuscation; play; sibling interaction; sibling conversation. 


\section{Acknowledgements}

The authors are indebted to Dr Juliette Corrin for her valuable comments on an earlier draft of this paper. 


\section{Introduction}

The research presented in this paper examines an older sibling's responses to verbal challenges of her talk or conduct made by her younger sibling during free-play. The term challenge encompasses otherinitiated linguistic repair, factual disagreements, and procedural queries about the parameters of the play, e.g.:

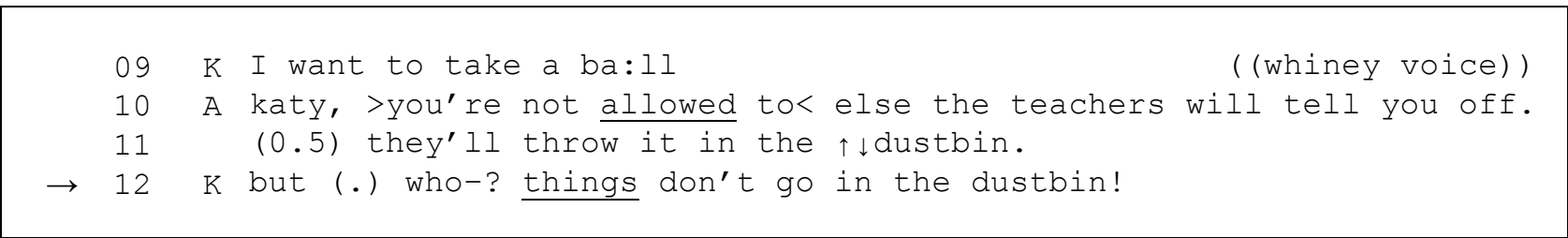

\section{Repair and Agreement in Conversation}

The significance of challenges in children's talk is revealed in Sidnell's description of conversational repair as 'part of the mechanism by which children set standards and police norms for one another's conduct and [...] use of language' (Sidnell, 2010: 123). That is, challenges represent a form of peer socialisation, as will be discussed in the analysis. From a broader Conversation Analytic perspective, Schegloff et al present repair as an indispensable element in maintaining conversational intersubjectivity, describing it as 'the self-righting mechanism for the organization of language use in social integration' (1977: 381).

Among adult speakers, a preference for agreement in everyday conversation, and for so-called 'self-repair' over 'other-repair', has long been documented in the literature (Schegloff et al, 1977). Later research (e.g., Norrick, 1991) developed this model by postulating that the decision of whether and how to repair another's speech is sensitive to parameters such as the formality of the setting, the social relations between the participants, and the repair-initiator's assessment of the relative epistemic levels of each party. Speakers who are familiar with one another are more likely to initiate and repair each other's speech overtly, perhaps because they feel more at liberty to do so, or because informality leads to less-closely monitored speech containing more trouble-sources.

However, prominent studies of disagreement among children (Goodwin, 1983; Loyd, 2012) found that children's treatment of verbal challenge differs radically from that of adults: the preference that adults exhibit for avoiding or minimising disagreement is inverted in children's talk, which displays it overtly 'exposed correction', in Jefferson's terms (1987). 


\section{Play and Child Development}

The age-range of the dyad in this study $(3 ; 3$ to $6 ; 11)$ corresponds with an important period in children's peer interaction and language development (Howe et al, 2014). During this transition from early to middle childhood, children refine their ability to recognise others' points of view and to negotiate - key factors shaping their interactions.

This growing sophistication is reflected in children's play. By five years of age, for example, their roleplay with others often includes physically absent third-parties, and their developing symbolic skills enable them to use toys in imaginative ways (Howe \& Bruno, 2010). Children's expanding vocabularies and increasingly precise syntax allow for these elaborate play scenarios to be communicated to their playpartners.

Children's naturally occurring play in the home environment has long been recognised as important for their social-emotional, language, and cognitive skills (Vygotsky, 1966), yet remains an under-researched area (Howe et al, 2011). The context of the four interactions examined in the present study is imaginative play, which entails reciprocity and negotiation as the participants collaborate to advance the play scenario (Göncü, 1993).

\section{The Sibling Relationship}

The sibling relationship differs fundamentally from other child-child relationships: due to the extensive time siblings typically spend together, they grow to know each other intimately and establish a 'sibling culture'. It has been estimated that by the time a younger sibling reaches the age of three, a 'tipping point' is reached, after which the siblings spend more time interacting with each other than with anyone else (Haight \& Miller, 1992). This underscores older siblings' important role as agents of socialisation (Zukow, 1989).

DeHart (1996: 83) notes that the sibling relationship 'often combines strong feelings of affection with equally strong feelings of hostility and envy.' The rivalrous element may relate to asymmetries arising from the age difference and consequent disparities in developmental level, experience and power. Leach et al (2015) note the obligatory nature of sibling relationships (in contrast to peer relationships). They suggest this permanence may be what accounts for the reduced levels of prosocial behaviours observed between siblings. DeHart (1996) agrees that a key difference between sibling- and peer-relationships is that presenting oneself as socially acceptable is less of a priority between siblings, consistent with Phinney's (1986) observation that explanations and compromises are less common among siblings than peers.

Disagreement is a facet of sibling relations that has attracted research interest, and one traditionally construed as negative. But the notion of 'constructive conflict' - disagreements resolved to the 
satisfaction of both parties through negotiation - suggests that challenge may enrich sibling relations (Howe et al, 2002).

Despite its implication in the acquisition of a broad range of social skills, sibling interaction has been the subject of far fewer studies than, for example, parent-child or teacher-child interaction, perhaps due to issues of restricted access to participants, or a Western bias towards formal school settings (de Leon, 2007). There is a particular dearth of CA studies on sibling talk in the home environment ${ }^{1}$; instead, much of the existing research takes the form of clinic-based experiments comprising researcher-devised tasks, which does to some degree limit the ecological validity of the findings. More specifically still, Howe et al (2002) identify sibling conflict-resolution during early- and middle childhood as an under-investigated area. The present study aims to address these gaps.

Taken together, the material in the sections above presents a puzzle: how do siblings engaged in imaginary play navigate between the conflicting forces of collaboration (required to maintain the play frame) and disagreement, towards which they as siblings are often predisposed?

\section{Birth Order and Interaction}

In terms of features we might expect to find in conversations between siblings, differences between older and younger siblings' communicative behaviour have been noted. In broad terms, older siblings' utterances are typically more directive, whereas younger siblings display a more cooperative, consensual style (McGillicuddy-De Lisi, 1993). Howe and colleagues (2005) found that older siblings (aged seven) use various strategies to secure cooperation, including extending younger siblings' ideas and making invitations (e.g., Do you want to...?). The younger siblings (aged four) were observed to prefer simpler strategies (e.g., calling to gain attention) and paralinguistic devices (e.g., sound-effects). Another study hypothesises that younger siblings, used to interacting with relatively unresponsive older siblings, develop a 'persistent' communicative style to elicit responses, or produce a high proportion of speech forms that require a response, such as direct questions (Barton \& Tomasello, 1994). McIntosh and Punch (2009: 55) note that the age difference can result in a 'smaller range of tactics to draw on' for the younger sibling, suggesting a limited repertoire of strategies with which to challenge older siblings.

However, other research contends that power dynamics in sibling interactions are not necessarily a function of birth order, and that sibling hierarchies are far more fluid than parent-child relations (Abuhatoum \& Howe, 2013). From their interviews with 90 children aged between five and 17, McIntosh and Punch (2009) conclude that the power traditionally associated with older siblings is in fact often contested, resisted or negotiated. Likewise, Kent (2012) urges researchers to examine the specifics of each interaction rather than assume particular status hierarchies. Another factor, which may shape the

\footnotetext{
${ }^{1}$ Exceptions include de Leon (2007), Goodwin (2017), and Hester \& Hester (2010).
} 
challenges examined in this study, relates to the age of the younger sibling: the preschool years are a stage in which younger siblings' developing cognitive and communicative skills enable them to become more active participants in sibling interactions, prompting a shift from a more hierarchical relationship towards a more reciprocal, egalitarian relationship (Abuhatoum \& Howe, 2013). The present study's focus on challenges initiated by a younger sibling, rather than corrections issued by an older sibling, may provide insights into a possible subversion of traditional hierarchies, as will be seen in the analysis.

\section{Method}

\section{Participants and Setting}

This case-study presents in-depth qualitative analysis of naturally occurring interactions between 'Anna' and 'Katy', a dyad of typically-developing siblings engaging in free-play at home. The home setting provides high ecological validity. The participants are the children of the first author. The analysis is based on video footage recorded over approximately 15 months. In June 2014, at the beginning of this period, Anna is aged $5 ; 8$ and Katy $3 ; 3$. Anna had completed her first year of primary school and Katy had been attending preschool for six months.

\section{Procedure}

\section{Data Collection}

Approval for the study was obtained from the UCL Research Ethics Committee and consent was given by the participants' parents. The siblings were recorded playing together without adult participation. Footage was recorded when the children became engaged in naturally-occurring play sequences. This was possible as the setting was the researcher's home. During recording, to minimise external influences on the children's behaviour, the researcher remained in an adjacent room and made only brief responses if the participants initiated interaction with her.

The data corpus comprises 19 recordings, totalling four hours of footage. Recordings range in length from two to 30 minutes. Five of the recordings are audio-only, due to the recording device being positioned so as to avoid disrupting interactions already in progress.

\section{Transcription and Analysis}

In accordance with the data-driven approach of Conversation Analysis, the video recordings were viewed repeatedly, in a process of 'unmotivated looking' to identify phenomena of interest (Psathas, 1995). This resulted in the emergence of the theme of verbal challenges originating from the younger sibling, for example querying the accuracy of an assertion by her older sister. These were notably rarer than corrections from the older sibling, so were judged to be potentially interesting for further investigation. 
All instances of challenge from the younger sibling were catalogued then transcribed orthographically, in accordance with CA conventions (Jefferson, 1984a). This produced a collection of 20 challenge exemplars. In addition to the participants' talk, transcripts include non-verbal elements such as gestures, to capture the requisite degree of detail about the interaction. Additional comments were made in right-justified double-brackets where required, for instance to clarify referents of deictic terms. The participants are identified in the transcripts by their pseudonym initial.

The older sibling's challenge-responses were compared and commonalities identified. Four extracts that illustrate the phenomena of interest have been selected for line-by-line analysis. The analysis focuses on the older sibling's responses to challenges rather than the challenges themselves, as responses have received less coverage in the literature (Phinney, 1986). This is also more in keeping with the emphasis CA places on next-turns to provide proof of actions being performed.

\section{The Use of Conversation Analysis}

Conversation Analysis (CA) posits that conversation is a collaborative enterprise in which each participant's turn displays an orientation to, and an understanding of, their co-participant's preceding talk (Sacks et al, 1974). CA is based on the premise that conversations are made up of highly organised sequences, and CA's primary endeavour is to reveal organisational patterns through systematic analysis (Schegloff, 2007). Its focus remains practical: how speakers design their utterances to accomplish particular social actions.

CA's consideration of non-verbal as well as verbal elements of communication makes it well suited to a study of children at play, whose gestures and manipulation of props are significant components of their interactions. The degree of detail included in CA transcriptions captures aspects of communication that may otherwise be overlooked. This is particularly important in fast-tempo interactions between typically-developing children who know each other well.

\section{Analysis}

\section{Challenge Rejection}

In Extract 1 the siblings are playing 'schools': it is the start of a new school year and Anna is playing a teacher who is about to start as Katy's class teacher. At this point in the play scenario, they are preparing to leave for school and Anna is drawing a picture as a leaving gift for her previous class. This extract shows the older sibling dismissing the younger sibling's (valid) challenge by alluding to the disparity in their levels of knowledge and experience, then performing a variety of social actions (correcting, narrating, predicting, advising) to hold the floor and prevent further dissent. 


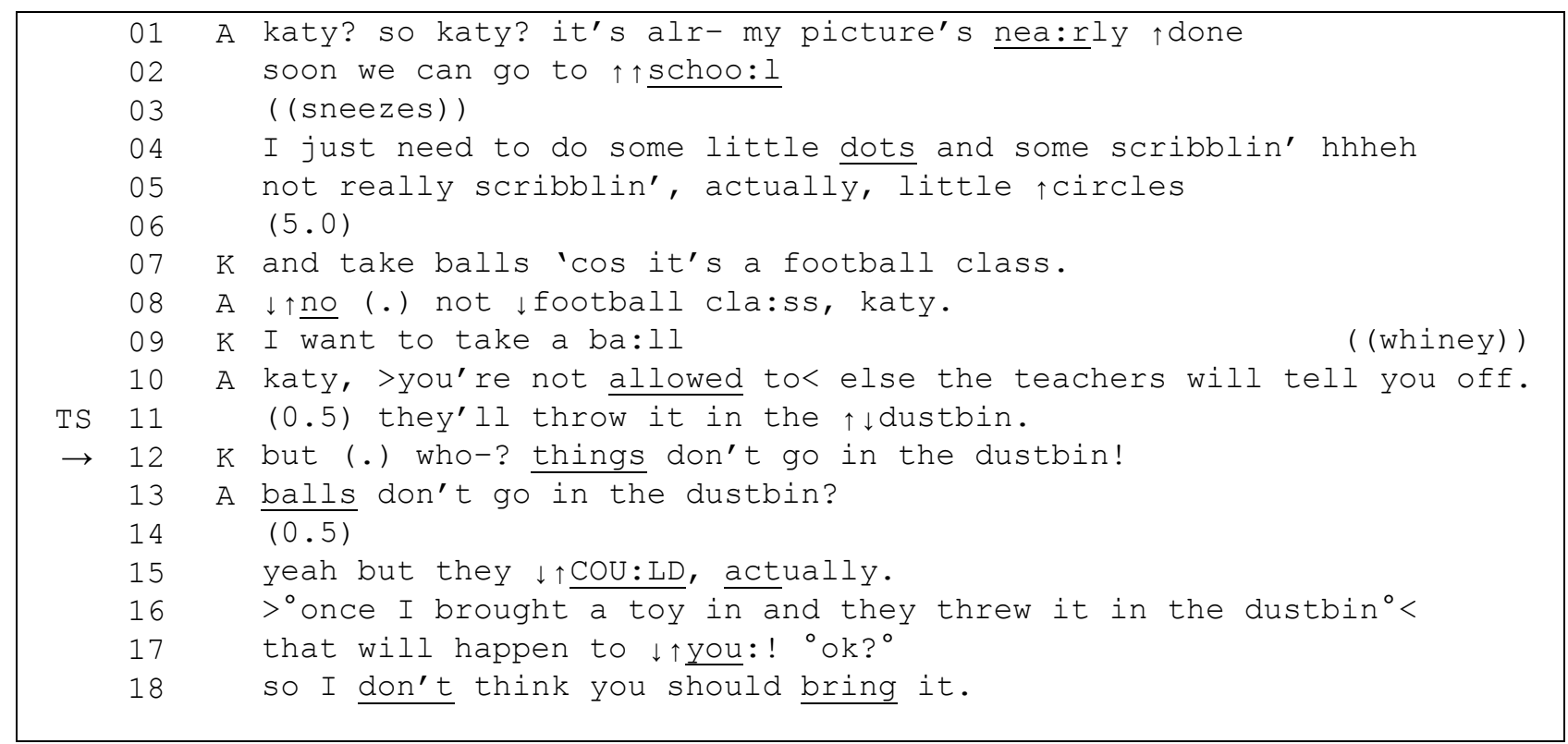

In lines 1-5 Anna narrates her activity of drawing and proposes that the next sequence in the play be around leaving for school (L2). At L7 Katy attempts to co-construct the play narrative, extending the theme of leaving for school by suggesting that Anna take a ball, as the first lesson that morning is football. Anna rejects this suggestion through a direct negation and an assertion that Katy is mistaken about the class timetable (L8): $\downarrow \uparrow n o($.$) not \downarrow$ football cla:ss, katy. The fall-rise intonation of $\downarrow \uparrow n o$ and naming of the addressee are characteristic of teacher talk, in keeping with the role allocation, and alluding to the disparity in status between the siblings' roles (teacher and pupil).

At L9, Katy shifts the agent of the ball-taking from Anna to herself. At L10 Anna again addresses Katy by name and asserts you're not allowed to, making an implicit reference to a higher authority: the school rules. Anna extends this topic by stating that the consequence of infringing school rules is being 'told off'. Anna's specification that it would be the teachers who would administer the 'telling off' appears somewhat at odds with the premise that Anna is Katy's teacher. However, this depersonalisation has the effect of altering the dynamics of the dispute, from Anna versus Katy to a (plural) third party versus Katy, thus reducing the confrontation between the siblings. After a brief pause Anna presents a further reason for not bringing a football to school (L11): the teachers will throw it away. Katy, at L12, challenges this assertion, identifying it as a trouble source. She starts to question the agent of the supposed throwing-

\footnotetext{
${ }^{2}$ Trouble sources are identified in the left-hand column of the transcripts by 'TS' and challenges are arrowed.
} 
away but (.) who-?, which she self-corrects to a statement rejecting the general proposition that teachers throw objects other than waste into dustbins.

Rather than addressing the content of Katy's challenge, Anna's initial response (L13) seeks clarification of the referent of one of the words contained within the challenge (things). There is reason to hypothesise, however, that this next-turn repair-initiator may not be the genuine enquiry it purports to be, as the referent (the ball) had recently been named (L9) and referred to pronominally (L11). Arguably, Anna's repair carries an implicit rebuke for under-specification or inaccuracy (as of course some things can indeed be thrown in the dustbin), so could represent a correct verbal model and an attempt to foreground her younger sister's inferior level of linguistic competence. The brief pause at L14 lends support to this interpretation, as it does not constitute sufficient time for Katy to self-repair things. This phenomenon of Anna correcting Katy's linguistic errors (replacing things with balls) occurs elsewhere in the data set but is not examined further in this paper.

Anna's extended turn across L15-L18 serves to refute Katy's assertion that teachers don't throw away pupils' possessions. An interesting internal progression can be noted: Anna's initial Yeah (L15) acknowledges the validity of Katy's challenge in L12, it is followed by a conditional statement, a gloss of which could read: 'Even if something sounds unlikely, it nonetheless could occur'. The actually is a marker of epistemic certainty that presents Anna's talk as revealing a fact about the world, underscoring her role as teacher to Katy's pupil, or her status as the more experienced participant. In the following turnconstructional-unit (L16) Anna adopts a different stance: she aligns herself with Katy by citing an example of when she, too, suffered the loss of a personal possession at the hands of a teacher. L17 contains a stark warning: that will happen to $\downarrow \uparrow y$ you:!, in which the philosophical tone of the conditional tense (L15) is replaced with the bold certainty of the future tense and the emphatic specificity of you:!. In the final part of Anna's sequence, $\mathrm{L} 18$, the force is tempered by a measured, advisory tone. At this point Katy withdraws from the conversation and starts handling an object in the vicinity.

\section{Obfuscation of Challenges}

Having examined an exemplar of the younger sibling's challenge being rejected, we now consider another type of response from the data set: obfuscation. In the three extracts that follow, Anna is seen to 'side-step' Katy's challenge by inserting an extended turn that engages Katy and distracts her from her challenge.

Extract 2: Obfuscated challenge: 'Little Kitty's not fat' (Anna aged 5;9, Katy aged 3;3) 
In this sequence, Anna and Katy are again playing schools. Anna has the role of class teacher and Katy is her assistant. Assembled teddies represent the pupils. It is the birthday of one of the pupils and a celebratory party is being held. Cake has just been distributed.

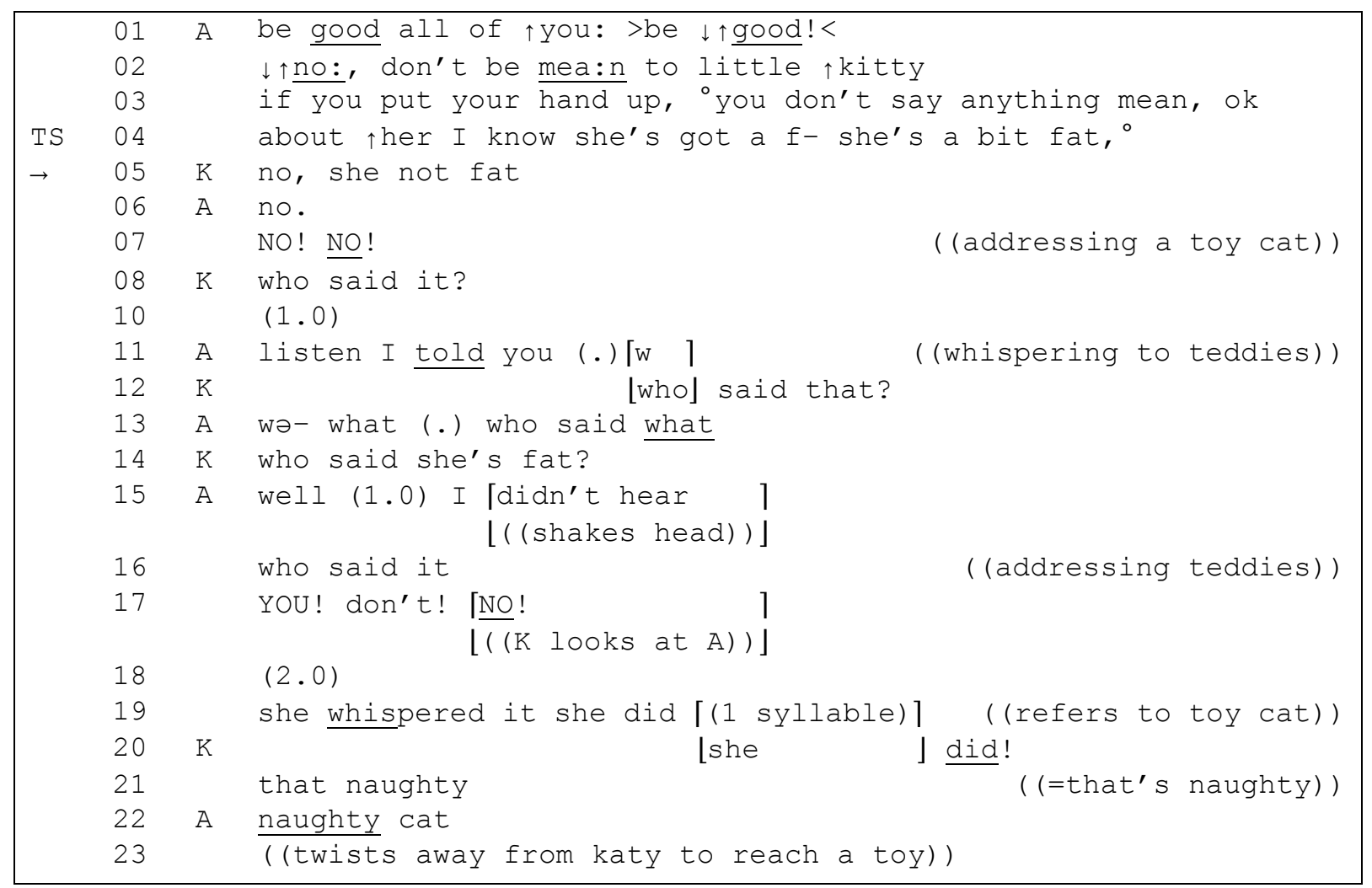

The extract starts with Anna addressing the teddies. Her exaggerated 'sing-song' intonation, emphasis on evaluative words (good, L1), and reference to classroom practices (raising a hand before being permitted to speak) mark this as teacher talk. The sequence of imperatives over L1-L3 suggest that the social action Anna is seeking to accomplish is the establishment of authority. With the $\downarrow$ 个no: (L2) Anna admonishes some (imaginary) instance of unsanctioned behaviour directed at Little Kitty, one of the pupils, and evaluates the behaviour as be[ing] mean (L3).

In L4, Anna (as teacher) acknowledges that Little Kitty may be a bit fat. The introductory I know... is a reference to shared knowledge about the world (Heritage, 2012), which could be interpreted as a rhetorical device to sympathise with a pupil's potential justification for calling Little Kitty fat, before potentially explaining that calling people names is nonetheless an unacceptable behaviour. The high-level pitch contour at the end of L4 supports this interpretation, suggesting that the phrase is incomplete, i.e., that a second part (such as ...but that's no reason to call her names.) remains implicit. The reduced volume at which L4 is produced, and the insertion of the qualifier a bit in the reformulated version of the assertion (she's a bit fat) attenuates the force of the utterance, and could display the speaker's orientation to the potentially objectionable nature of its content. 
Katy's challenge (L5) identifies L4 as a trouble source and performs disagreement with great economy (Goodwin, 1983): she rejects the preceding turn's assertion (no) then proposes an alternative assessment (she not fat). Alluding to moral principles when disagreeing, as is done in this turn, is a strategy that has been observed in younger siblings in other recent research (Abuhatoum \& Howe, 2013).

Anna's immediate response to this challenge is an agreement token no. (L6); Anna accepts Katy's proposed view - in direct contradiction of her own previous turn - and concedes that Little Kitty is not, in fact, fat - or indeed that pragmatically it would be inappropriate and implausible for a teacher to suggest so to a class. With NO! NO! (L7) Anna upgrades her opposition to the proposition contained in the trouble source by publicly and emphatically reprimanding one of the teddies for having allegedly uttered the comment. This shift in attribution performs the social action of rapidly distancing Anna (in the role of teacher) from the trouble source, thus avoiding censure.

Katy's following turn, Who said it? (L8), requests that Anna identify the speaker of the trouble source. Anna does not respond to Katy; instead, following a pause (L10), she continues to address the teddies, scolding them for disobeying her prior directive not to be mean. Her whispered production implies collusion between the teacher and the class, as if Anna sympathises with their evaluation that Little Kitty is overweight, but that she too has been reminded of the need to adhere to the social rules which prohibit such a comment from being made.

In the absence of an answer to her question from L8, the overlapping talk in L11-L12 shows Katy taking the floor at a transition-relevance place to repeat the question originally asked in L8, substituting a more emphatic deictic term (that) for the previous proform (it). Anna's response (L13) displays initial dysfluency, followed by Who said what?. This question from Anna is feigning ignorance as to the referent of Katy's questions and can be viewed as a defensive move to further distance herself from the act of uttering the offending talk. The evidence for this is that Katy perseveres in her line of questioning: Who said she's fat? (L14), this third time making explicit the referent of the previous proforms it and that. In L15 Anna responds with the discourse marker well - an initiator of a dispreferred response to a wh-question and face-threat mitigator (Jackson \& Jones, 2012). Anna's claim at L15 to have been unable to hear who said the utterance in question is a further attempt to distance herself from it, and the claim is difficult for Katy to refute. This denial of knowledge as a defence, a phenomenon also observed in an older sister by Goodwin (2017), is made more emphatic by Anna's accompanying head-shake. At L16 Anna redirects the talk towards the teddies rather than responding to Katy - a deflection technique observed previously at L7 and L11.

Anna self-selects as next speaker at two transition-relevance places (L15-16; L16-17). This prevents Katy from taking the floor and avoids the risk of further interrogation or challenges of inconsistencies in her account. Eventually Anna does reply to Katy (L19), identifying the culprit as the toy cat she had accused 
with YOU! (L17). Anna reinforces the epistemic certainty of her accusation with the tag clause she did. At L20 Katy repeats this tag phrase emphatically (she did!), accepting Anna's accusation of the toy cat; Katy then evaluates the cat's alleged behaviour (that['s] naughty, L21). In the final turn of this extract, Anna repeats and extends Katy's term naughty, reiterating that the cat is the agent of the objectionable behaviour. Anna turns away from the play to retrieve another toy, signalling that the matter is resolved. Katy's following turn shifts the topic to the distribution of the remaining cake.

In this extract it is notable how promptly Anna begins interactional work to distance herself from the trouble source (L4) upon being challenged about its appropriateness. The persistence with which Katy pursues her line of questioning forces Anna to deploy strategies in quick succession to obfuscate the fact that it was in fact she (as teacher) who uttered the problematic term, fat. These strategies are considered further in the Discussion section below. The imperative for Anna to distance herself from the trouble source may be motivated by a need to avoid censure and ultimately maintain authority within the game, even if this sacrifices a degree of plausibility (e.g., claiming ignorance about the referent of Katy's questions (L13)) or introduces pragmatic incongruity (e.g., self-contradictions (L4/L6)). 
Extract 3: Obfuscated challenge 'Why are you so much older than me?' (Anna aged 5;8, Katy aged 3;3)

This extract comes from the beginning of an episode of play, as roles are being allocated. Anna is assigning herself the role of teenage sister/teacher and Katy the role of pupil. The challenge from Katy questions why the age-difference between their characters in the game is greater than it is in reality.

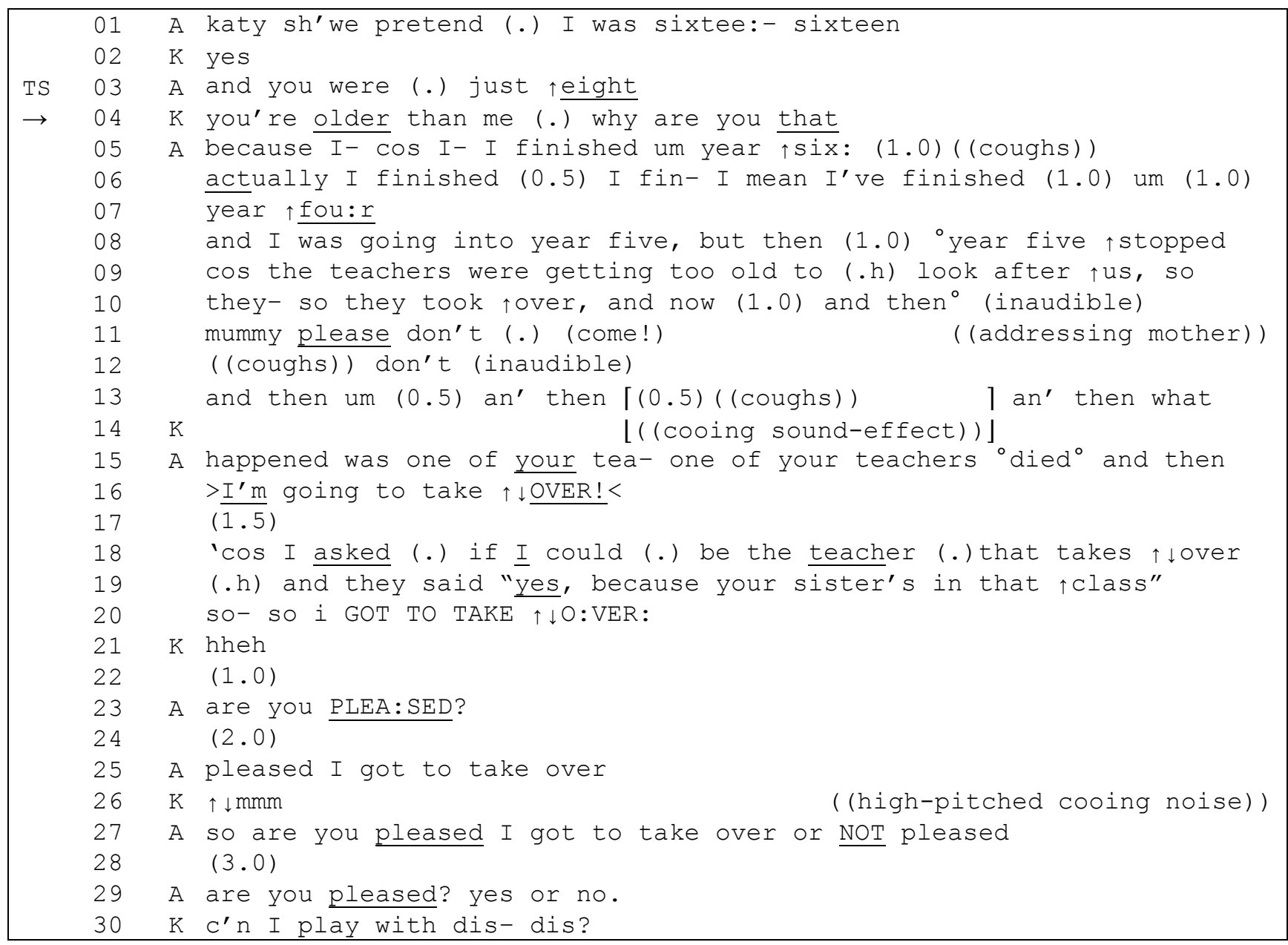

At L1 Anna proposes an age for her own character (sixteen). This receives prompt agreement from Katy (L2). The trouble arises when Anna proposes that Katy's character be just eight - creating a significantly wider age-gap then the two years that separate the siblings in reality. Indeed, the preface just indicates that Anna recognises that eight is a younger age than might be expected. Evidence supporting this interpretation can be found in the rising intonation of eight, which conveys a tentative stance, as if anticipating that this age-suggestion may prove more contentious than the preceding one. Katy's challenge (L4) comprises a statement noting the discrepancy in age, followed by a request for an explanation.

There follows a lengthy extended turn from Anna (L5-L20). Its initial word because acknowledges Katy's question and presents the extended turn as a response. The extended turn begins with statements of which school year Anna's character is in (L5-L8). Her repeated specification that she has finished the 
various years (L5-L6) reinforces her status as the older, more experienced participant. This section of talk is characterised by numerous hesitations and self-corrections - possibly because the speaker's familiarity with the school system extends only to Year 6 . The implausibility of Anna's claim that a 16-year-old would be in Year 6 or indeed Year 4 may be licensed by the difference in the participants' epistemic levels: Anna is aware that Katy is yet to start school, so is unlikely to be in a position to challenge the factual accuracy of school-related talk. The rising intonation placed on words at the end of successive turn-constructional units (six (L5), four (L7), stopped (L8), us (L9), over (L10)) signal to Katy that the turn is ongoing, so should not be interrupted.

The drop in volume from midway through L8 coincides with a further departure from the real towards the pretend frame in the turn's content: that Anna's character is permitted to stop attending school as her teachers are getting too old (L9).

At L15-L16 Anna announces the unexpected news that Katy's teacher dies and so Anna has been drafted in to replace him/her. Her hushed delivery in narrating the teacher's demise may indicate an orientation to it being a taboo topic. The dramatic nature of these suggestions, the quick succession in which they are introduced, and the marked intonation contour on the final word ( $\downarrow$ OVER! L16) suggest that following various interruptions (L11-14) this is an attempt by Anna to recapture Katy's attention which her sound-effect (L14) indicated may have been waning.

At the transition-relevance place in L17 there is no audible uptake from Katy following this dramatic plot development. Anna self-selects as next speaker and continues the narrative with a post-expansion explaining why she was offered the particular teaching post (L19). The school's purported justification for appointing Anna to this role is given as being the sisters' familial connection. This making explicit of the decision-making process of an authoritative third-party (the headteacher) can be interpreted as a device with which Anna seeks to persuade Katy that this appointment is a legitimate, logical course of action in an institution such as a school, and hence prevent further challenges.

At L20 Anna reissues her announcement from L16: so i GOT TO TAKE $\downarrow$ O:VER:, this time with added emphasis. The use of the to get to construction presents the role allocation as a fortuitous opportunity, rather than something of Anna's design.

Katy's vocalisation at L21 appears to be unsatisfactory for Anna, for she prompts Katy to elaborate, through her question are you PLEA:SED? (L23). The positive formulation and strong emphasis on PLEA:SED? indicate that the question is 'type-specifying' (Schegloff, 2007: 78) designed to elicit a preferred response of yes.

Following a two-second silence at L24, Anna reformulates her question, making its referent fully explicit: pleased I got to take over (L25). Katy's vocalisation at L26 $\downarrow \downarrow m m m h$ is an acknowledgement 
token, its marked rise-fall intonation implying general acquiescence with Anna's request for approval. However, L27 shows that Anna is seeking a more explicit declaration of support: she reissues the question as a fully expanded forced-choice, the two permitted responses (pleased or not pleased (L27)) receiving additional emphasis. The so (L27) functions as an attempt by Anna to return to the question originally asked at L23. A lengthy silence ensues (L28). Katy's failure to respond at this point leads Anna to issue her question a fourth time (L29), in a succinct and direct formulation informing Katy that a minimal Yes/No response would suffice.

This sequence of reformulations of a single question (L25/27/29) could be viewed as 'scaffolding' to facilitate the younger sibling's understanding. Alternatively, the progression of increasingly closed questions can be interpreted as a device to narrow down the field of possible responses for Katy, obliging her with increasing insistence to provide a positive evaluation to the news, which could bring the sequence to a close. Katy's refusal to provide the projected response may grant her a sense of control over the play scenario, but, through obfuscation, Anna has succeeded in neutralising Katy's original challenge about their pretend ages.

In this extract, Katy's challenge calls on Anna to account for the eight-year age-gap she is proposing between their respective play characters. Far from minimising this disparity in status that has been identified as problematic, Anna heightens it by elevating her character from older sibling to teacher. Likewise, the social action targeted by Anna becomes more ambitious as the interaction progresses: she starts by seeking basic consent to her proposed role-allocation; this evolves to requesting an unequivocal expression of enthusiasm towards it. Although she fails to secure the latter, she tacitly secures the former. 


\section{Extract 4: Obfuscated challenge: 'Sprinkling glitter' (Anna aged 6;9, Katy aged 4;4)}

In this final extract, Anna and Katy have constructed a play scenario in which they have built a home for some toy unicorns. Anna has been mixing together glitter of various colours. The intention is to feed the glitter mixture to the unicorns, which will imbue them with magical powers.

\begin{tabular}{|c|c|c|c|}
\hline 01 & & $\mathrm{~K}$ & $\mathrm{OOH}$ can I- can I $\left[\frac{\text { also sprinkle it }}{\mid(\text { (reaches for glitter pot) }]}\right.$ \\
\hline 02 & TS & A & $>\underline{\text { NO }}$ KATY $!<$ \\
\hline 03 & $\rightarrow$ & K & ${ }^{\circ}$ why? ${ }^{\circ}$ \\
\hline 04 & & A & becau:se $(0.5)^{\circ}>$ that's what I say $<^{\circ}$ \\
\hline 05 & & & ( ('they'=pots of glitter)) \\
\hline 06 & & $\mathrm{~K}$ & $(($ whiny) ) \\
\hline 07 & & A & โy'know」 what happens if somebody sprinkles some a bit too [much?] \\
\hline 08 & & $\mathrm{~K}$ & [what?] ( (whiny) \\
\hline 09 & & A & you: will be qui:te scared of this: \\
\hline 10 & & $\mathrm{~K}$ & $(($ looks up at $A$ for 2.0 secs $))$ \\
\hline 11 & & A & did you know? \\
\hline 12 & & $\mathrm{~K}$ & what? \\
\hline 13 & & A & do you think monsters exist \\
\hline 14 & & K & ${ }^{\circ} \mathrm{n}:: 0 ?^{\circ}$ \\
\hline 15 & & A & do you think monsters are real? \\
\hline 16 & & K & ${ }^{\circ} \mathrm{n}:: \mathrm{O}^{\circ}$ \\
\hline 17 & & A & 'that's actually wrong. the truth is, they a:re. ${ }^{\circ}$ \\
\hline 18 & & & it's just >no-one's ever seen one before< \\
\hline 19 & & & I know it's a bit-it's a bit unbelievable that they a:re (.) real, \\
\hline 20 & & & but it's true because I've see:n one actually \\
\hline 21 & & $\mathrm{~K}$ & $\uparrow \downarrow$ where \\
\hline 22 & & A & $(1.0)$ oh it was rea:lly sc(hh) ary \\
\hline 23 & & $\mathrm{~K}$ & did you- did you (.) like it? \\
\hline 24 & & A & >yeah was really good!< $<\downarrow$ watching $\uparrow$ it. but it ${ }^{\circ}$ nearly killed some \\
\hline 25 & TS & & people. ${ }^{\circ}$ I (h) uckily, I saved them. \\
\hline 26 & $\rightarrow$ & K & ((shakes head)) \\
\hline 27 & & A & nah just joking dinosaurs aren't real or (.) [monsters] aren't real \\
\hline 28 & & $\mathrm{~K}$ & [monsters] \\
\hline 29 & & & $(2.0)$ \\
\hline 30 & & A & >just made a good story though< \\
\hline 31 & & & ((starts humming to self)) \\
\hline
\end{tabular}

The extract starts with Katy requesting permission from Anna to join in the mixing of the glitter. At L2 Anna issues an unequivocal refusal (NO KATY!). At reduced volume, Katy then challenges Anna's decision by requesting an explanation (L3). Anna's Because... (L4), acknowledges that an explanation is expected of her. After a brief pause, she completes the turn with a formulaic expression, ...that's what I say! (L4). This phrase, typically associated with the talk of parents to children, positions Anna as the figure of authority in the interaction. It acts to dismiss Katy's challenge, implying that an explanation is not necessary. However Anna then relents by providing a more specific reason, saying of the glitter pots: They're mine! (L5). This 
unelaborated claim of ownership rights over the glitter is not contested by Katy, but she does vocalise an expression of disappointment (L6).

At this point Anna's approach changes. One could speculate that this is prompted by the whining quality of Katy's response cry - a potential precursor to withdrawal from the play. L7 is a critical point in the interaction, and performs several actions. Anna enquires, adopting a breathy tone of voice, whether her younger sister is aware of the consequences of someone inadvertently sprinkling too much glitter. The references to epistemics ( $y^{\prime}$ know what happens if [...]?), to judgements of acceptable standards (too much), and the thinly veiled insinuation that Katy would prove less proficient than Anna at mixing the glitter, further position Anna in the role of expert. The impact of this accentuation of epistemic disparity is, however, modulated by Anna's 'confiding' tone, the solidarity inherent in the reference to a unnamed common peril, the depersonalisation in the selection of the term someone rather than you, and by the mitigator $a$ bit. L7 also shifts the topic of the talk from the immediate physical actions of the game to a removed hypothetical scenario. L7 functions as a sequence-initiator (Heritage, 2012), suggesting that a narrative can follow, should the interlocutor so wish. This function is evidenced at $L 8$ by Katy's solicit turn what?, which grants Anna permission to proceed with her narrative, and constitutes a tacit undertaking that Katy will attend to it.

Rather than beginning the narrative at this point (L9), Anna opts to defer it by inserting a second pre-beginning: you: will be qui:te scared of this. Like L7, this serves to secure Katy's attention and heighten her anticipation of the talk to follow, while also warning her about its scary content, generating a sense of foreboding. The prosodic emphasis on you: further invokes disparity between the siblings' roles in the interaction, contrasting an older, knowing, storyteller with a younger, more impressionable, child.

At L11 Anna inserts a third pre-beginning: did you know? - a partial repeat of the initial one (L7) but this time with its referent unspecified. The shift to the past tense could be viewed as a transition from the real to the unreal, as L1 of Extract 3 sh'we pretend I was sixteen signals the start of the imaginative frame (Garvey, 1993) through a proposal of irrealis. Alternatively, the past tense of L11 could allude to Katy's 'unknowing position' (Heritage, 2012: 32) prior to a forthcoming revelation.

L11 elicits a second 'permission token' from Katy at L12, and at L13 Anna reveals the long-heralded topic (monsters), but in the form of a further pre-sequence question. The prolongation, reduced volume, and marked pitch-rise of Katy's response $\left({ }^{\circ} n:: 0 ?^{\circ}, L 14\right)$ indicate tentativeness and hedging: she does not think that monsters exist, but - as at L8 and L12 - she is giving Anna permission to elaborate.

The adjacency pair of L13-L14 is then repeated almost verbatim at L15-L16; it could be posited that in her substitution of are real (L15) for exist (L13), Anna is scaffolding for her younger sister by equating the more advanced term exist with the more accessible be real. Alternatively, the two terms could be being 
employed interchangeably, in an act of pure repetition, in which case Anna is displaying an awareness of the rhetorical effect of repetition: building anticipation, engaging the listener, and - crucially for this interaction - distracting the listener from the previous topic.

As the tentative tone of Katy's ${ }^{\circ} n:: 0 ?^{\circ}(\mathrm{L14} / 16)$ predicts, Anna refutes the statement of belief about the world which it posits, and produces an unequivocal counter-claim in support of the existence of monsters (L17). This turn, spanning L17-L20, contains multiple allusions to epistemic certainty: actually [...] the truth is [...] it's true. Anna then pre-empts potential assessments of the announcement from Katyspecifically, challenges around plausibility (L19), and concludes by offering proof: it's true because I've seen one actually. Acoustically, Anna's turn allows no pauses at transition-relevance places, and turn completion units are terminated on stressed lengthened syllables (e.g., a:re, L17) and display intonation patterns indicating continuation (e.g., real, L19); Anna is manipulating the boundaries of the transition-relevance places in order to hold the floor.

At L21, Katy asks a factual question about Anna's claimed sighting of a monster. This is received with a brief pause and the discourse marker oh, used to mark reception and create coherence between speaker turns (Fuller, 2003). Anna's subsequent response (L22) describes the emotive quality of the encounter, reiterating the concept of 'scariness' introduced at L9 and reinforced by its whispered delivery, yet avoids answering Katy's specific question.

Katy adopts Anna's affect-oriented focus, enquiring whether Anna liked seeing the monster (L23). Anna's response (L24-L25) comprises three elements: a statement that it was an enjoyable experience, a somewhat contradictory elaboration that it was a dangerous encounter, and a claim that she saved other people's lives. The incongruity between the elements of this sequence appears to strain the degree of credulity that Katy is prepared to grant Anna's story - evidenced through Katy's head-shake (L26). This embodied action can be interpreted as a non-confrontational yet robust challenge to Anna's narrative. Anna recognises this challenge by readily conceding that her account was indeed fabricated: nah just joking (L27). By framing her narrative as non-serious, Anna is performing facework (Gerholm, 2011), justifying the sequence with reference to the entertainment it provided (made a good story though, L30).

Anna signals that the episode is over by starting to hum to herself.

In sum, in this extract Anna obfuscates Katy's challenge through a stepwise topic-shift (Jefferson, 1984b), from procedural discussion about rights to mix glitter, to an alleged sighting of a monster.

Structurally, Anna's topic-shift is achieved through a series of pre-sequences. Its question-answer pairs (L78/11-12/13-14/15-16) prove an effective device with which to secure Katy's active participation in the digression and - crucially - obfuscate her original challenge, rendering return to it increasingly onerous. Semantically, the segment is characterised by frequent references to epistemics, linking possession of 
knowledge with control over the interaction. The actions performed by the topic-shift are discussed in the following section.

\section{Discussion}

In this section we identify features of Anna's challenge-responses and consider the underlying actions they perform (rejection or obfuscation of the challenge) so as to address the 'puzzle' posed earlier: how an older sibling, upon being challenged, manages the conflicting forces of collaboration and disagreement.

\section{Face Preservation}

A preliminary remark is that Katy's challenges in all four extracts are well founded - if somewhat anchored to reality rather than pretence. They query the veracity of far-fetched statements (e.g., that teachers discard pupils' possessions), disagree with assessments (e.g., that a particular teddy is fat), and challenge injustices (e.g., that glitter-sprinkling can only be performed by Anna). Yet the data examined contain only one overt acknowledgement from Anna that she stands corrected: regarding her claim to have fended off a monster. It is perhaps noteworthy that this challenge had been expressed by Katy nonverbally, through embodied action alone, so possibly perceived by Anna as less of a face-threat. Anna's climb-down (nah just joking) invoked humour then justified the trouble source by indexing the entertainment value it provided (made a good story though). Anna's dispreference, across the data set, for acknowledging correction supports Phinney's (1986) finding that concession among siblings is rare, and provides some evidence that siblings attach great importance to face-preservation. Anna's response-types are consistent with Gerholm's (2011) finding that five-/six-year-olds' facework is predominantly performed verbally.

As such, Anna's interactional strategies to deflect Katy's challenges, identified below, can be viewed as pragmatic devices to avoid face-loss.

\section{Features of Challenge-Responses}

\section{Epistemic Differentials}

A tendency among older siblings to adopt the role of 'expert' is well established (Zukow, 1989). In each extract examined here, Anna brings to the fore 'information imbalances' (Heritage, 2012: 32) between her and Katy. This is done in two distinct ways: by alluding to her (character's) position of authority or greater experience, or by indexing privileged information pertinent to the grounds of the challenge. 
The former is accomplished through a variety of techniques, for example by adopting an adult

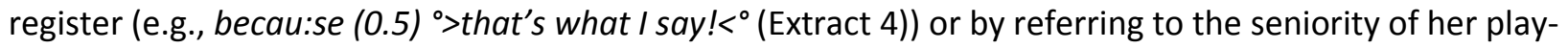
character (e.g., as one of the oldest children in the school: I finished um year $\uparrow$ six: (Extract 3)). The latter approach is displayed in Extract 2 when Anna claims access to knowledge about the identity of the play character who uttered the trouble source (YOU! [...](2.0) she whispered it she did).

Anna contrasts her and Katy's epistemic positions more explicitly in Extract 4 'Sprinkling glitter', in response to Katy's tentative assertion that monsters are not real: 'that's actually wrong. the truth is, they a:re. ${ }^{\circ}$. Anna's series of pre-announcements flouts the principle that announcements generally follow a single pre-announcement at the earliest opportunity, and serves to heighten the epistemic differential through repeated use of verbs of knowledge (know, think).

\section{Exaggeration within Pretence}

A second feature common to all Anna's challenge-responses are exaggerated or implausible assertions, which dramatise her narrative, transforming it into a 'performance' (Drew, 2003). These farfetched claims perform a variety of local functions: in Extract 1 'Balls don't go in the dustbin!' and Extract 4 'Sprinkling glitter', Anna's implausible claims (that a teacher once threw away her toy; that she has seen a monster) provide evidence in support of an assertion she made earlier in the turn (that Katy will lose her ball; that monsters exist) and warn Katy of the consequences of disobeying Anna's wishes. Anna's implausible claim in Extract 3 (that a pupil was drafted in to replace an ageing teacher) is a means of justifying the age-gap between the two play characters in order to defend her proposal against Katy's challenge.

Alternatively, it could be argued that these challenges from Katy breach the 'rules' of pretend play: that she is revealing her relative immaturity by adhering to 'mundane reasoning', failing to grasp that pretence is an interactive context in which reality is temporarily suspended. One way of explaining this phenomenon is in Goffman's (1974) terms: that in order to make sense of the interaction, Katy is framing her challenges as challenges to reality rather than remaining within the footing of the pretend-play scenario. Thus, in Extract 1, Anna's use of the hypothetical (but they $\downarrow \uparrow C O U: L D$, actually (L15)) to underline the reality disjuncture (Heritage \& Clayman, 2012) indicates an awareness that Katy holds a different footing from her own: that of participant rather than play-character. In broader terms, L15 could thus constitute evidence of Anna, through challenge-response, socialising Katy about distinctions between framing interactions as either 'pretend' or 'real' to enable her to make sense of the play experience.

\section{The Obfuscation Response}


A salient structural feature of Anna's 'Obfuscation responses' presented above (Extracts 2-4) is the extended turn in which they occur. Here we identify other features that characterise the three exemplars.

\section{Prosodic Variation}

Anna sustains her extended turns in a number of ways, one of which involves prosody. There is evidence that children of this age are able to interpret prosodic cues in relation to turn-taking patterns (Keitel et al, 2013), and in Extract 3 Anna adopts a 'listing' rising intonation to hold the floor across successive transition-relevance places (e.g., L5/7/8/9/10).

Prosody is further employed by Anna through marked variations in volume, tempo and voice quality. This acoustic juxtapositioning is illustrated most strikingly in a sequence in Extract 2 (L6-L11), in which Katy's assertion that Little Kitty is not overweight is received initially with muted agreement (no.), followed by an emphatic NO! NO!, followed by a stage-whisper (listen I told you...).

Anna's announcement of dramatic news or taboo topics, such as characters' injury or untimely death, is relayed at reduced volume (Extract 3, L15; Extract 4, L24). Elsewhere, overtones of 'scariness' are encoded through breathy voice (Extract 4, L17/22). Such tone-of-voice modulations at with key points in narratives signal a change in the affective valency of the topic, and serve to maximise listener engagement.

\section{Multiplicity of Voices}

In each of the Obfuscation sequences, repeated switching of addressee is a defining feature. In Extract 2 'Little Kitty's not fat': Anna alternates between directing her talk at Katy and the teddies. This injects the sequence with tempo and unpredictability, forcing Katy to work harder to interpret the discourse. The resulting uncertainty, evidenced in repeated clarification-requests from Katy, serves to distract Katy from the fact that it was Anna (as teacher) who uttered the trouble source.

In Extract 3 'Why are you so much older than me?' Anna cites the speech of the headteacher (L19) to justify her position. This bringing in of an authoritative source 'sanctions' Anna's proposed storyline, and exemplifies what Drew (1998: 302) terms 'defensive detailing', displaying a speaker's orientation to the possibility that his/her talk could be regarded as containing some sort of moral transgression which must be rebutted. Similarly, in Extract 4, Anna adopts her co-participant's perspective when, having claimed that monsters exist, she pre-empts a potential objection: I know it's a bit-it's a bit unbelievable that they a:re (.) real, (L19). This move forestalls interruption from Katy, allowing Anna to proceed and present further evidence in support of her claim about monsters (L20).

\section{Interlocutor Involvement}

Anna begins her obfuscation digression in Extract 4 'Sprinkling glitter' by initiating a sequence of QA adjacency pairs (L7-L16), each of which invites a monosyllabic response from Katy. Verbal participation 
from Katy is also secured towards the closure of Anna's digression in Extract 3 (L23-L29), similarly designed to elicit only minimal responses from Katy (are you pleased? yes or no). The listener contributions elicited draw Katy into the topic of the digression and away from her original challenge.

\section{Actions Performed by Obfuscation}

\section{Transforming the Social Action}

The combined effect of the mechanisms outlined above is to distract Katy with elaborate and engaging digressions, to obfuscate her challenges. This supports the findings of DeHart et al (2001) that faced with verbal conflict, older siblings approaching middle childhood are more likely to employ distraction strategies rather than 'stand firm'. It also corroborates the findings of Phinney (1986) that at this stage older siblings become increasingly adept at deploying elaborate conversational moves in response to challenges.

Further, Anna's digressions transform the conversational business from addressing a challenge to recounting a narrative. Sidnell (2010), too, describes a phenomenon whereby children respond to challenges by transforming the social action, through the introduction of laughter. Obfuscation has been identified in a recent CA study as a phenomenon observed in the talk of teachers at parents' evenings when criticising the student (Pillet-Shore, 2016). As in the present study, the obfuscation described by Pillet-Shore entailed extra interactional work and was designed to forestall conflict, maintain cooperation, and avoid face-threat.

\section{Blurring of Distinctions}

The value that children attach to self-determination and retaining control has been documented previously (Kent, 2012; Loyd, 2012). In the present study, the imperative for the older sibling to retain control when challenged, even when not triggering a full obfuscation sequence, leads to a blurring of boundaries between the social actions being performed. As outlined above, all four challenge-responses considered share several features. Indeed, it proves difficult to distinguish an acceptance from a rejection. Anna's 'rejection' of the challenge in Extract 1 'Balls don't go in the dustbin!' is equivocal: her yeah but preface accepts the validity of the challenge, placating Katy, but she then rejects the challenge by establishing an epistemic gradient: they $\downarrow \uparrow \underline{C O U: L D}$, actually. This yes but strategy of prefacing a refusal with an agreement token has been noted previously: Garvey (1993) found it to occur more frequently among older (> 4;2 years) than younger dyads. Sheldon (1992) theorises that yes but is a manifestation of a broader phenomenon, 'double-voice discourse', found in girls' negotiation talk, in which their pursuit of their own agenda is tempered by an orientation to their co-participant's perspective and a desire to maintain the cohesion of the group. 
In obfuscating Katy's challenges rather than accepting or rejecting them, Anna avoids the dual pitfalls of, respectively, (i) relinquishing control; or (ii) threatening progressivity by creating conflict that could cause Katy to disengage from the play. The latter is an undesirable outcome for siblings in the home setting in particular, as alternative play partners may not be readily available.

On close inspection, Anna's challenge-responses classified as obfuscations all begin as acceptances (Extract 2) or rejections (Extract 3; Extract 4). The obfuscatory sequence appears to be triggered when indicators of pitfalls (i) or (ii) described above become manifest, such as Katy's expression of disappointment and potential disengagement at L6 of Extract 4.

In sum, the obfuscation response marks a departure from the traditional dichotomous framework of compliant versus non-compliant second-position responses, towards a more nuanced alternative that displays the speaker's awareness of both participants' perspectives in navigating between the polar acceptance-rejection positions (Sheldon, 1996). The younger sibling's challenges appear to flout the adult norm of preference for agreement; however, the older sibling's responses reveal a more adult-like orientation to the need to mitigate disagreement through deployment of subtlety (Sheldon, 1992; Zukow, 1989). This contrasts to the overtly confrontational displays between children in multi-party interactions observed by Goodwin (1995) and Loyd (2012). It may be that our findings are specific to middle-class girls' dyadic interactions, so further conversation analytic studies examining challenge between siblings from other cultures and genders would be welcome.

\section{Conclusions}

This study's findings provide insight into the complexity of a five-/six-year-old's challenge-defence strategies during imaginative play with her younger sibling. They provide some evidence that an awareness of adult norms in conversational interaction - face-preservation and mitigation of opposition - can be present at an early age. Furthermore, building on earlier work (e.g., Garvey, 1993), we propose that the ability to respond to verbal challenges whilst maintaining intersubjectivity is a component of children's communicative competence. 


\section{References}

Abuhatoum, S., \& Howe, N. (2013). 'Power in sibling conflict during early and middle childhood'. Social Development, 22(4): 738-754.

Barton, M., \& Tomasello, M. (1994). 'The rest of the family: the role of fathers and siblings in early language development'. In C. Gallaway, \& B. Richards (Eds.) Input and interaction in language acquisition. Cambridge: Cambridge University Press.

DeHart, G. (1996). 'Gender and mitigation in 4-year-olds' pretend play talk with siblings. Research on Language and Social Interaction', 29(1): 81-96.

DeHart, G., Kilpatrick, L., Betjemann, S., Bernadt, M., Stenger, S., Sullivan, K., \& Westerling, L. (2001). 'Conflict and averted conflict between siblings and friends in early and middle childhood'. Poster session presented at the biennial meeting of the Society for Research in Child Development, Minneapolis.

de León, L. (2007). 'Parallelism, metalinguistic play, and the interactive emergence of Zinacantec Mayan siblings' culture'. Research on Language and Social Interaction, 40(4), 405-436.

Drew, P. (1998). 'Complaints about transgressions and misconduct'. Research on Language and Social Interaction, 31: 295-325.

Drew, P. (2003). 'Precision and exaggeration in interaction'. American Sociological Review, 68: 617-638.

Fuller, J. (2003). 'The influence of speaker roles on discourse marker use'. Journal of Pragmatics, 35(1): 2345.

Garvey, C. (1993). 'Diversity in the conversational repertoire: The case of conflicts and social pretending'. Cognition and Instruction, 11(3-4): 251-264.

Gerholm, T. (2011). 'Children's development of facework practices'. Journal of Pragmatics, 43: 3099-3110.

Goffman E. (1974). 'Frame analysis'. Cambridge: Harvard University Press.

Göncü, A. (1993). 'Development of intersubjectivity in the dyadic play of pre-schoolers'. Early Childhood Research Quarterly, 8: 99-116.

Goodwin, M. H. (1983). 'Aggravated correction and disagreement in children's conversations'. Journal of Pragmatics, 7(6): 657-677.

Goodwin, M. H. (1995). 'He-said-she-said: Talk as social organization among Black children'. Bloomington: Indiana University Press.

Goodwin, M. H. (2017) 'Sibling sociality: Participation and apprenticeship across contexts'. Research on Children and Social Interaction, 1: 1-26.

Haight, W., \& Miller, P. (1992). 'The development of everyday pretend play: a longitudinal study of mothers' participation'. Merrill-Palmer Quarterly, 38(3): 331-49.

Heritage, J. (2012). 'The epistemic engine: Sequence organization and territories of knowledge'. Research on Language \& Social Interaction, 45(1): 30-52. 
Heritage, J., \& Clayman, S. (2012). 'Melvin Pollner: A view from the suburbs.' The American Sociologist, 43(1): 99-108.

Hester, S., \& Hester, S. (2010). 'Conversational actions and category relations: An analysis of a children's argument'. Discourse Studies, 12(1): 33-48.

Howe, N., Abuhatoum, S., \& Chang-Kredl, S. (2014). "'Everything's upside down. We'll call it upside down valley!" Creative play themes, object use, and language during pretend play'. Early Education and Development, 25: 381-398.

Howe, N., \& Bruno, A. (2010). 'Sibling pretend play in early and middle childhood: the role of creativity and maternal context'. Early Education and Development, 21(6): 940-962.

Howe, N., Rinaldi, C., Jennings, M., \& Petrakos, H. (2002). '"No! The lambs can stay out because they got cozies": constructive and destructive sibling conflict, pretend play, and social understanding'. Child Development, 73(5): 1460-73.

Howe, N., Ross, H., \& Recchia, H. (2011). 'Sibling relations in early and middle childhood'. In P. Smith \& C. H. Hart (Eds). The Wiley-Blackwell handbook of childhood social development (2nd ed). Chichester: Wiley-Blackwell.

Jackson, C., \& Jones. D. (2012). 'Well they had a couple of bats to be truthful: Well-prefaced, self-initiated repairs in managing relevant accuracy in interaction'. Journal of Pragmatics, 47(1): 28-40.

Jefferson, G. (1984a) 'Transcription Notation'. In J. Atkinson \& J. Heritage (Eds.), Structures of Social Interaction, New York: Cambridge University Press.

Jefferson, G. (1984b). 'On stepwise transition from talk about a trouble to inappropriately next-positioned matters'. In J. M. Atkinson \& J. Heritage (Eds.) Structures of social action. Cambridge: Cambridge University Press.

Jefferson, G. (1987). 'On exposed and embedded correction in conversation'. In G. Button \& J. Lee (Eds.). Talk and social organization. Clevedon: Multilingual Matters.

Keitel, A., Prinz, W., Friederici, A., Von Hofsten, C., \& Daum, M. (2013). 'Perception of conversations: The importance of semantics and intonation in children's development'. Journal of Experimental Child Psychology, 116(2): 264-77.

Kent, A. (2012). 'Compliance, resistance and incipient compliance when responding to directives'. Discourse Studies, 14(6): 711-730.

Leach, J., Howe, N., \& DeHart, G. (2015). 'An earthquake shocked up the land!' Children's communication during play with siblings and friends'. Social Development, 24(1): 95-112.

Loyd, H. (2012). 'The logic of conflict: The rhetoric of resilience among inner-city Neapolitan girls.' In M. Theobald \& S. Danby (Eds.), Disputes in everyday life: Social and moral orders of children and young people (325-353). Bingley: Emerald Group Publishing.

McGillicuddy-De Lisi, A. (1993). 'Sibling interactions and children's communicative competency'. Journal of Applied Developmental Psychology, 14(3): 365-383.

McIntosh, I, \& Punch, S. (2009). "'Barter", "deals", "bribes" and "threats": Exploring sibling interactions'. Childhood: A Global Journal of Child Research, 16(1): 49-65.

Norrick, N. (1991). 'On the organization of corrective exchanges in conversation'. Journal of Pragmatics, 16: 59-83. 
Phinney, J. (1986). 'The structure of 5-year-olds' verbal quarrels with peers and siblings'. The Journal of Genetic Psychology, 147(1): 47-60.

Pillet-Shore, D. (2016). 'Criticizing another's child: How teachers evaluate students during parent-teacher conferences'. Language in Society, 45, 1: 33-58.

Psathas, G. (1995). Conversation analysis: The study of talk-in-interaction. Thousand Oaks: SAGE.

Schegloff, E. (2007). Sequence organization in interaction: A primer in conversation analysis. Cambridge: Cambridge University Press.

Schegloff, E., Jefferson, G., \& Sacks, H. (1977). 'The preference for self-correction in the organization of repair in conversation'. Language, 53(2): 361-382.

Sheldon, A. (1992). 'Conflict talk: sociolinguistic challenges to self-assertion and how young girls meet them'. Merrill-Palmer Quarterly, 38(1): 95-117.

Sheldon, A. (1996). 'You can be the baby brother but you aren't born yet: preschool girls' negotiation for power and access in pretend play'. Research on Language and Social Interaction, 29(1): 57-80.

Sidnell, J. (2010). 'Questioning repeats in the talk of four-year-old children'. In H. Gardner \& M. A. Forrester (Eds.) Analysing interactions in childhood: Insights from conversation analysis. Chichester: WileyBlackwell.

Vygotsky, L. (1966). 'Play and its role in the mental development of the child'. In M. Cole (Ed.), Soviet developmental psychology (76-99). New York: Sharpe.

Zukow, P. (1989). 'Siblings as effective socializing agents: Evidence from central Mexico'. In P. G. Zukow (Ed.), Sibling interaction across cultures: Theoretical and methodological issues (79-105). New York: Spring-Verlag. 